\title{
Study on verification of various national standards regarding phthalate testing in industrial products
}

\author{
Moon Hwan Song, Young Dal Cho, Eun Kyung Choe` and Young Chan Myoung ${ }^{1}$ \\ Product Eco-testing Laboratory, Korea Institute of Industrial Technology, Ansan, Gyeonggi 426-910, Korea \\ ${ }^{1}$ Korean Agency for Technology and Standards, Gwacheon, Gyeonggi 427-723, Korea \\ (Received March 23, 2012; Revised June 6, 2012; Accepted June 6, 2012)
}

\section{공산품 중 프탈레이트류 함유량 분석법에 관한 국내외 표준의 검증 연구 \\ 송문환 · 조영달 · 최은경ᄎ · 명영찬 ${ }^{1}$ \\ 한국생산기술연구원 국제환경규제대응기술지원단 유해물질분석실 \\ 기술표준원}

(2012. 3. 23. 접수, 2012. 6. 6. 수정, 2012. 6. 6. 승인)

\begin{abstract}
As phthalates classified as toxic to reproduction category 2 and endocrine disrupting chemicals were more strictly regulated as Substances of Very High Concern (SVHC) for authorization in under EU REACH and considered as priority substances in RoHS II, standardization of phthalate testing method is now being proposed in IEC 62321 of IEC TC 111 and the 2nd revision of KS M 1991 is also finished. In order to assist standardization activities related to phthalating testing, solvent extraction part of existing national standards were compared and verified. Recovery of DEHP (diethylhexyl phthalate) from PVC (polyvinyl chloride) by Soxhlet extraction increased in the order of methanol, toluene, dichloromethane and hexane from $46.9 \%$ to $95.3 \%$ as measured by GC-MS. Optimum extraction time was verified to be 6 hours using hexane. Recovery of DBP (dibutyl phthalate), BBP (butylbenzyl phthalate), and DEHP from different matrixes such as PVC, nitro cellulose, ABS (acrylonitrile butadiene styrene). and EPDM (ethylene propylene diene monomer) rubber were evaluated to be more than $90 \%$ up to $99 \%$. The detection limits of phthalates in solvent extraction followed by GC-MS analysis were $0.08 \sim 0.3 \mu \mathrm{g} / \mathrm{mL}$ in solution and $8 \sim 30 \mathrm{mg} / \mathrm{Kg}$ in polymeric samples. GC-MS analyses of phthalates were carried out using different solvent extraction based on the EN 14372, ASTM D 7083, Japanese test method (MHLW 0906-4) and KS M 1991, proving that equivalent recoveries ranging from $98 \%-99 \%$ were obtained. DBP and DEHP were detected in three consumer products such as a child toy, a power cable and manicure with the amount of $22 \sim 1,910 \mathrm{mg} / \mathrm{kg}$.
\end{abstract}

요 약: 생식독성 및 내분비계 장애물질로 분류되는 프탈레이트가 근자에 유럽 신화학물질관리제도 $(\mathrm{REACH})$ 의 허가대상 고위험성 물질(SVHC) 목록 및 유럽의 전기전자제품에 함유된 유해물질 규제인 RoHS II의 최우선 고려 물질 등으로 규제가 강화되면서 IEC TC 111에서 분석법 표준화가 진행되고 있

$\star$ Corresponding author

Phone : +82-(0)31-8040-6211 Fax : +82-(0)31-8040-6230

E-mail : ekchoe@kitech.re.kr 
으며 $\mathrm{KS}$ 개정도 이루어지고 있다. 본 고에서는 프탈레이트 분석법의 $\mathrm{KS}$ 개정 및 한국 $\mathrm{NC}$ 에서 제안하 여 진행되고 있는 IEC 62321에 프탈레이트 분석법을 추가함에 있어 기술적 자료로 사용될 수 있도록 현 존하는 국가별 표준의 용매 추출 전처리를 비교 및 검증해 보았다. PVC (polyvinyl chloride)에서의 DEHP (diethylhexyl phthalate)의 추출 효율은 메탄올, 톨루엔, 디클로로메테인. 헥세인 순으로 $46.9 \%$ 에서 95.3\%까지 증가하였다. DBP (dibutyl phthalate), BBP (butylbenzyl phthalate) 및 DEHP의 속슬렛을 사용한 추출 시간은 6시간이 최적임이 입증되었고, PVC, nitro cellulose, ABS (acrylonitrile butadiene styrene). and EPDM (ethylene propylene diene monomer) rubber 등의 매트리스로부터의 추출 효율도 $90 \%$ - $99 \%$ 로 측정 되었다. 용매추출에 이은 GC-MS 분석법의 검출한계는 용액 및 고분자 샘플에서 각각 $0.08 \sim 0.3 \mu \mathrm{g} / \mathrm{mL}$ 및 $8 \sim 30 \mathrm{mg} / \mathrm{kg}$ 으로 산출되었다. 공산품에서 프탈레이트를 분석하는 국가표준에서 용매 추출 전처리를 사용하는 EN 14372, ASTM D 7083, 일본 후생노동성 시험법(MHLW 0906-4) 및 KS M 1991을 비교한 결과 4 개 국가별 표준 모두 $98 \%$ 99\%의 추출효율을 가짐이 검증되었다. 또한, 국내에서 유통되는 어린 이 장난감, 전기 코드, 매니큐어의 공산품 3종에서 프탈레이트 함유 여부를 분석한 결과 DBP 및 DEHP 가 $22 \sim 1,910 \mathrm{mg} / \mathrm{kg}$ 범위로 검출되었다.

Key words: phthalate testing, solvent extraction, recovery, GC-MS, Korea Standard, International Standard, polymeric materials, industrial products

\section{1. 서 론}

생식독성(toxic for reproduction) 및 내분비계 장애 물질(endocrine disrupting chemicals)로 분류되는 프탈 레이트는 $1-3$ 어린이용품, 식품 포장재, 화장품 분야에 국내외적으로 사용이 규제되어 온 유해물질이다.4-11 DBP (dibutyl phthalate), BBP (butylbenzyl phthalate) 및 DEHP (diethylhexyl phthalate)의 3종 프탈레이트는 2007년 6월 시행된 REACH(Registration, Evaluation, Authorization and Restriction of Chemicals, 유럽 신화 학물질관리제도)에서 2008년 10월 발표한 허가후보 SVHC (Substances of Very High Concern, 고위험성 물질)의 첫 목록인 15종 물질에 포함되었고, 2011년 2 월 허가대상 $\mathrm{SVHC}$ 가 되어 $\mathrm{REACH}$ 부속서 XIV에 등재되어, 허가받지 못한 용도에 대해서는 사용 금지 가 되는 물질이 되었다. ${ }^{12-14}$ 2006년 7월 시행된 유럽 의 RoHS (Restriction of the use of certain hazardous substances in electrical and electronic equipment)에 이 어서 유해물질 규제가 더 강화된 RoHS II에서도 $\mathrm{DBP}, \mathrm{BBP}, \mathrm{DEHP}$ 가 최우선 고려 물질이다. ${ }^{15-16} \mathrm{DINP}$ (di-iso-nonyl phthalate), DIDP (di-isodecyl phthalate), DNOP(di-n-octyl phthalate)는 미국(Consumer Products Safety Improvement Act), 캐나다(Canada Consumer Products Safety Act), 일본(후생청), 유럽(REACH 제 한물질 목록)에서 입에 넣어 사용할 용도의 공산품에

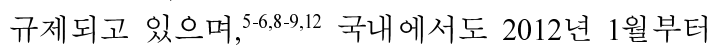

품질경영 및 공산품 안전관리법에 따른 “어린이용 공 산품에 대한 공통적용 유해물질의 안전기준”이 적용 되면서 DINP, DIDP, DNOP 3종의 총 함유량이 $0.1 \%$ 이하여야 하는 안전기준이 적용됨으로써, 어린이 공산 품에 대한 프탈레이트 안전관리가 “자율안전확인대상 공산품 안전기준”에서 보다 더 강화되었다. ${ }^{17} \mathrm{DIBP}$ (di-iso-butyl phthalate)는 REACH 허가후보 SVHC 목 록으로 발표되어 있고, ${ }^{13}$ 섬유제품 에코라벨인 OekoTex Standard에서 규제하고 있다(Table 1). ${ }^{18}$

이와 같이 REACH 및 곧 시행을 앞 둔 RoHS II의 영향으로 프탈레이트는 전기전자제품 및 산업 전 분 야에 있어 법적인 규제가 생기게 되므로, 전기전자제 품에서의 프탈레이트 분석법 국제표준(International Standard)에 대해서도 관심이 집중되고 있다. 따라서, RoHS 6종 물질 분석에 관한 국제표준인 IEC 62321 을 제정한 IEC (International Electrotechnical Commission) $\mathrm{TC} 111$ 에서는 프탈레이트 항목의 분석법 표준화가 제 안되어 진행되고 있으며, ${ }^{19-20}$ 프탈레이트 분석 표준인 KS M 1991 개정도 2011년 12월 완성되었다. ${ }^{21-22}$

본 고에서는 KS M 1991 개정 및 IEC TC 111의 한 국 NC(National Committee)인 기술표준원에서 제안하 여 진행되고 있는, IEC 62321 국제표준에 프탈레이트 분석법을 추가하는 NWIP (New Working Item Project) 에 ${ }^{19}$ 기술적 자료로 사용될 수 있도록 공산품에서의 프 탈레이트 분석법을 조사하여, 이들 국가 표준에서 사 용하는 용매 추출 전처리를 비교 및 검증해 보았다. 


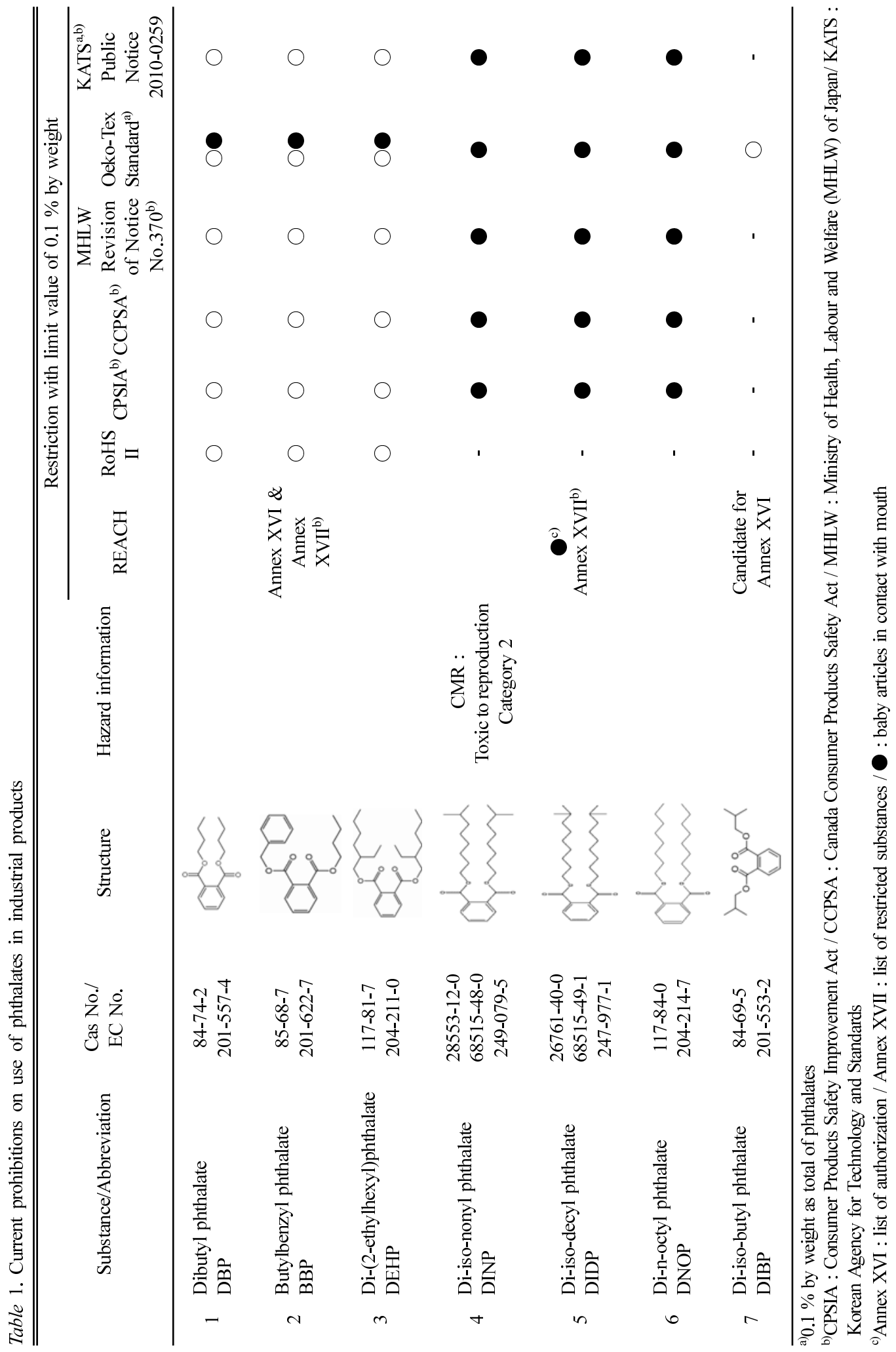




\section{2. 실 험}

\section{1. 시약}

Methanol, dichloromethane, toluene, hexane, diethyl ether, acetone은 GC급 (ACS, American Chemical Society grade)을 사용하였고, 헬륨은 순도 $99.999 \%$ 을 사용하 였다. DBP, BBP, DEHP 및 DIBP의 4종 프탈레이트 는 Sigma-Aldrich사에서 시약급(표준시약)으로 구입하 여 정제 없이 사용하였다.

\section{2. 장비 및 기기}

시료 분쇄에는 centrifugal mill (Pulverisette 14, Germany)을 사용하였고, 고분자 매질로부터 프탈레이 트 추출에는 $250 \mathrm{~mL}$ 용량의 속슬렛 장치가 사용되었 다. 프탈레이트의 정량분석에는 GC-MS(Gas Chromatography-Mass Spectometry) (Agilent, HP 6890, 검 출기 $\mathrm{MS}(5973 \mathrm{~N})$ )를 사용하였다. 반복성(repeatability) 을 위하여 자동시료 채취 장치를 사용하였다(Agilent, GC-MS 7683 series injector).

\section{3. 시료 샘플링}

용매 추출을 하기에 앞서 액상 시료의 경우는 유리 재질의 바이알에 시료를 놓고 약 $105{ }^{\circ} \mathrm{C}$ 오븐에서 건 조를 하였고, 고체 시료의 경우는 대략 $2 \mathrm{~cm} \times 2 \mathrm{~cm}$ 로 자른 후 centrifugal mill을 이용하여 입자의 크기를 $500 \mu \mathrm{m}$ 로 균일하도록 분쇄하였다.

\section{4. 회수율 산출 전처리}

\subsubsection{RM (reference material)}

추출 용매에 따른 $\mathrm{PVC}$ 에서의 프탈레이트 회수율 시험에는 DEHP가 $138,000 \mathrm{mg} / \mathrm{kg}$ 함유된 PVC 소 재의 RM(삼성전자 제조)이 사용되었다. 용매 추출 시 최적 시간 측정 시험 및 국내외 표준에 의한 3 가 지 용매 추출 조건 하에서 프탈레이트 회수율 산출 시험에는 DIBP, DBP, BBP, 및 DEHP 4종의 프탈레 이트가 함유된 EPDM (ethylene propylene diene monomer) rubber 소재의 $\mathrm{RM}$ (한국화학융합시험연구 원 제조, 프탈레이트 각 함유량 $5,000 \mathrm{mg} / \mathrm{kg}$ )이 사 용되었다.

2.4.2. 추출 용매 및 추출 시간에 따른 회수율 산 출을 위한 전처리

2.3.에 따라 균질하게 분쇄된 시료는 전자저울을 이 용하여 $2 \mathrm{~g}$ 을 측정한 후 셀룰로오스 재질인 원통형
추출 심블에 담아, 실험하고자 하는 각 용매(메탄올, 디클로로메테인(DCM), 톨루엔 및 헥세인) $100 \mathrm{~mL}$ 를 이용하여 시간 당 용매 순환속도가 6 8회가 되도록 온도를 맞추고 6 시간 동안 속슬렛으로 추출하였다. 이후부터는 최적 용매로 입증된 헥세인을 이용하여 속슬렛 추출 시간을 $2,4,6,8,10,12$ 시간으로 달리 하여 용매 추출을 수행하였다.

\section{3. 주요 매트리스로 부터의 회수율 산출을 위한 전처리}

PVC (polyvinyl chloride), Nitro cellulose, ABS (acrylonitrile butadiene styrene) 재질의 컴퓨터용 파워 케이 블, 여성용 매니큐어, 어린이 장난감을 구입하여 액상 시료인 매니큐어는 약 $105{ }^{\circ} \mathrm{C}$ 오븐에서 건조를 하였 고, 파워 케이블 및 자동차 장난감은 폴리머 재질을 분리하여 2.3.에 따라 분쇄하였다. 분쇄된 시료 $2 \mathrm{~g}$ 을 원통형 심블에 넣고 $\mathrm{DBP}, \mathrm{BBP}, \mathrm{DEHP}$ 의 표준용액(각 성분이 $1,000 \mu \mathrm{g} / \mathrm{mL}$ )을 스파이킹하여 성분별 $0.1 \%$ $(\mathrm{w} / \mathrm{w})$ 가 되도록 하였다. 스파이킹 전과 후의 시료를 2.4.2.에 따라 속슬렛 추출하였고(헥세인, 6시간 사용), 회수율은 측정 농도를 스파이킹 한 이론농도로 나누 어 백분율로 계산하였다.

24.4. 국가별 표준의 용매 추출 조건에서의 회수율 산출을 위한 전처리

2.4.1.의 $\mathrm{EPDM}$ rubber $\mathrm{RM}$ 을 사용하여 용매 추출 조건을 각기 달리한 $\mathrm{EN} 14372, \mathrm{ASTM} \mathrm{D} 7083$, 일본 후생노동성 시험법(MHLW 0906-4), KS M 1991에 따 라 프탈레이트를 전처리하여 GC-MS 분석한 후 회수 율을 산출하였다.

\section{5. 표준용액의 제조}

GC-MS 검 량곡선 작성을 위하여 4종 프탈레이트 표준용액을 제조하였다. EPA phthalate esters 혼합용 액(각 $2,000 \mu \mathrm{g} / \mathrm{mL}$, 헥세인)을 이용하여 $1.25,2.50$, $5.00,10.00,20.00 \mu \mathrm{g} / \mathrm{mL}$ 농도의 프탈레이트 3종 (DBP, BBP, DEHP) 표준용액을 제조하였고, hexane으 로 $1,000 \mu \mathrm{g} / \mathrm{mL}$ 농도의 $\mathrm{DIBP}$ 용액을 제조 한 후 $1.25,2.50,5.00,10.00,20.00 \mu \mathrm{g} / \mathrm{mL}$ 농도의 표준용액 을 제조하였다.

\subsection{GC-MS 분석}

속슬렛 추출에 의해 분석 대상물질인 프탈레이트를 추출한 후 기체크로마토그래피와 질량분석법으로 1 개 

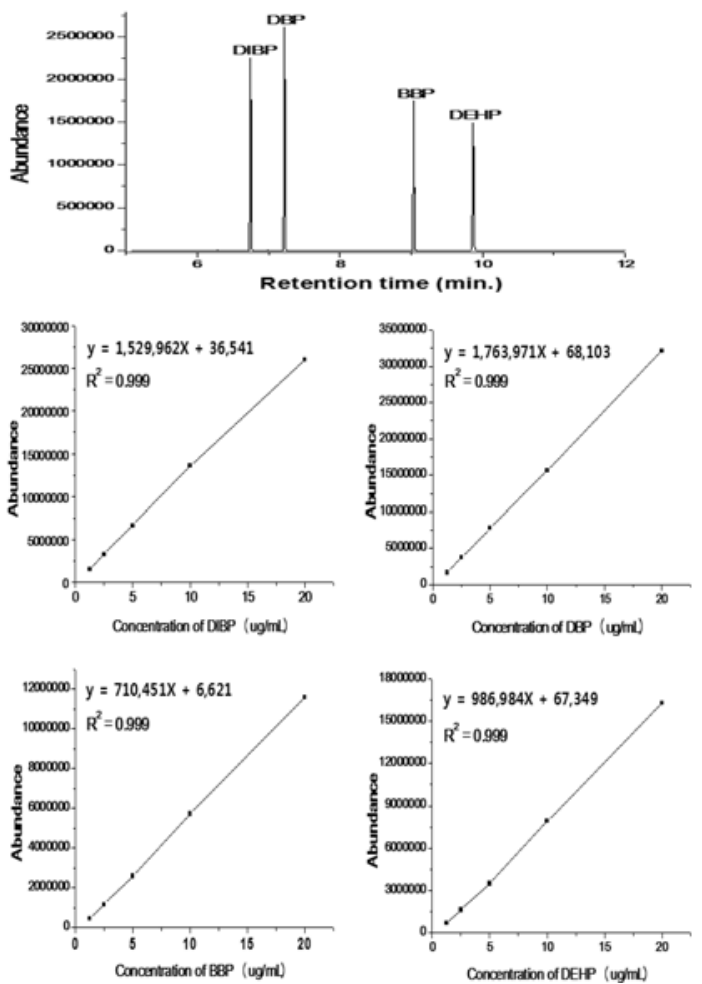

Fig. 1. GC-MS chromatogram of phthalates with their calibration curves.

의 시료에 대하여 전처리부터 3회 반복 분석하였다. $\mathrm{GC}$ 컬럼은 HP-5MS $(30 \mathrm{~m} \times 0.25 \mathrm{~mm}$ I.D. $\times 0.25$ $\mu \mathrm{m}$ film thickness)을 사용하였고 $\mathrm{GC}$ 의 온도 프로그 래밍은 $110{ }^{\circ} \mathrm{C}$ 에서 $20{ }^{\circ} \mathrm{C} / \mathrm{min}$ 으로 $280{ }^{\circ} \mathrm{C}$ 로 상승하 여 1 분 유지한 후 다시 같은 속도로 $320{ }^{\circ} \mathrm{C}$ 까지 상 승시킨 후 5 분간 유지하는 조건을 사용하였으며 $\mathrm{MS}$ 의 이온화원 등 주요 부분의 온도는 $300{ }^{\circ} \mathrm{C}$ 로 유 지하였다. $\mathrm{GC}$ 의 운반기체는 헬륨을 사용하여 1.5 $\mathrm{mL} / \mathrm{min}$ 으로 일정 유속을 사용하였다. 전자 이온화 법 $(\mathrm{EI}, 70 \mathrm{eV})$ 을 이용하여 총 이온전류 질량분석방 법(전 주사법)으로 물질을 확인한 후, 선택이온 검출 법(SIM, selected ion monitoring)을 이용해 정량되었 다 $(\mathrm{m} / \mathrm{z} 149$ 이용). 2.5.의 각 5 개 표준용액을 3 회 반 복 측정하여 검량곡선을 작성하였고(Fig. 1), 시료에 함유된 프탈레이트의 농도는 외부 표준물로 작성된 검량곡선에 의하여 계산하였다. 본 분석법의 검출한 계(LOD, limit of detection)는 검량곡선의 선형회기 식 $(\mathrm{Y}=\mathrm{aX}+\mathrm{b})$ 을 이용하여 아래 식과 같이 계산되었 고, ${ }^{2}$ 희석배수를 곱하여 고체 시료에 대한 검출한계 를 산출하였다.
$\mathrm{LOD}=3 \times[\Sigma(\text { Yei }-\mathrm{Yi}) 2 /(\mathrm{N}-2)]^{1 / 2} / \mathrm{b}$

Yei : 회기방정식에 의해 구한 각 표준용액의 반응값

$\mathrm{Yi}$ : 각 표준용액 측정 시 반응값

$\mathrm{N}$ : 표준용액 시료수

$\mathrm{b}$ : 회기방정식의 $\mathrm{X}$ 계수

\section{7. 대상 공산품 수집 및 프탈레이트 분석}

시장에서 임의로 수집된 공산품 3종을 2.3. 및 2.4.3 에 따라 헥세인을 이용하여 6시간 동안 속슬렛 추출 한 후 2.6.에 따라 GC-MS 분석을 행하여 프탈레이트 함유량을 측정하였다.

\section{3. 결과 및 고찰}

\section{1. 프탈레이트 분석법 국내외 표준 조사 및 비교}

공산품에 함유된 프탈레이트 분석의 국가 표준을 조사한 결과는 Table 2에 정리한 바와 같이, 어린이용 식탁용 도구, 장난감, 식품 포장재, $\mathrm{PVC}$ 등의 폴리머 재질에 함유된 프탈레이트를 정량 분석하는 방법으로 폴리머 재질에서 프탈레이트를 추출하는 전처리가 두 가지로 분류된다. ${ }^{24-29}$ 속슬렛 및 shaker를 이용한 용매 추출의 전처리(EN 14372, ASTM D 7083, 일본 후생 노동성 시험법(MHLW 0906-4)와 폴리머 매질을 THF 등의 용매에 용해(dissolution)시킨 후 헥세인 혹은 메 탄올을 첨가하여 폴리머를 침전시켜 여과하는 전처리 (미국의 CPCS-CH-C1001-09나 Canada method C-34) 를 한 후 주로 선택이온 검출법에 의한 $\mathrm{GC}-\mathrm{MS}$ 분석 을 행하고 있다.

근자에 개정된 KS M 1991 (고분자 재료 중의 프탈 레이트계 가소제 정량방법)의 주요 사항은 Table 3에 정리한 바와 같이, 분석대상 항목에 $\mathrm{DIBP}$ 가 추가되었 고 추출방법으로 기존의 속슬렛 용매 추출에 더하여 초음파 추출기 용출(매질을 테트라하이드로 퓨란 (THF)에 용해한 후 아세토나이트릴(ACN) 또는 메탄 올을 가하여 침전 후 여과하는 전처리)이 추가되었다. 기기분석은 GC-MS에 더하여 LC-MS가 추가되었는데 이는 피크의 머무름 시간이 4 6분에 걸쳐 다중피크로 검출되는 물질인 DIDP, DINP와 ${ }^{30}$ 다른 프탈레이트의 동시 분석을 더 용이하게 함이다(Table 3 ). ${ }^{21-22}$ 개정 표 준에서는 내부 표준물질을 사용하고 페인트나 잉크 등의 액체 시료는 $105{ }^{\circ} \mathrm{C}$ 오븐에서 건조하도록 되어 있고, LC-MS 분석에서 $\mathrm{DBP}$ 가 검출되면 $\mathrm{GC}-\mathrm{MS}$ 로 $\mathrm{DBP}$ 와 $\mathrm{DIBP}$ 이성질체 여부를 확인하고 각각 정량할 


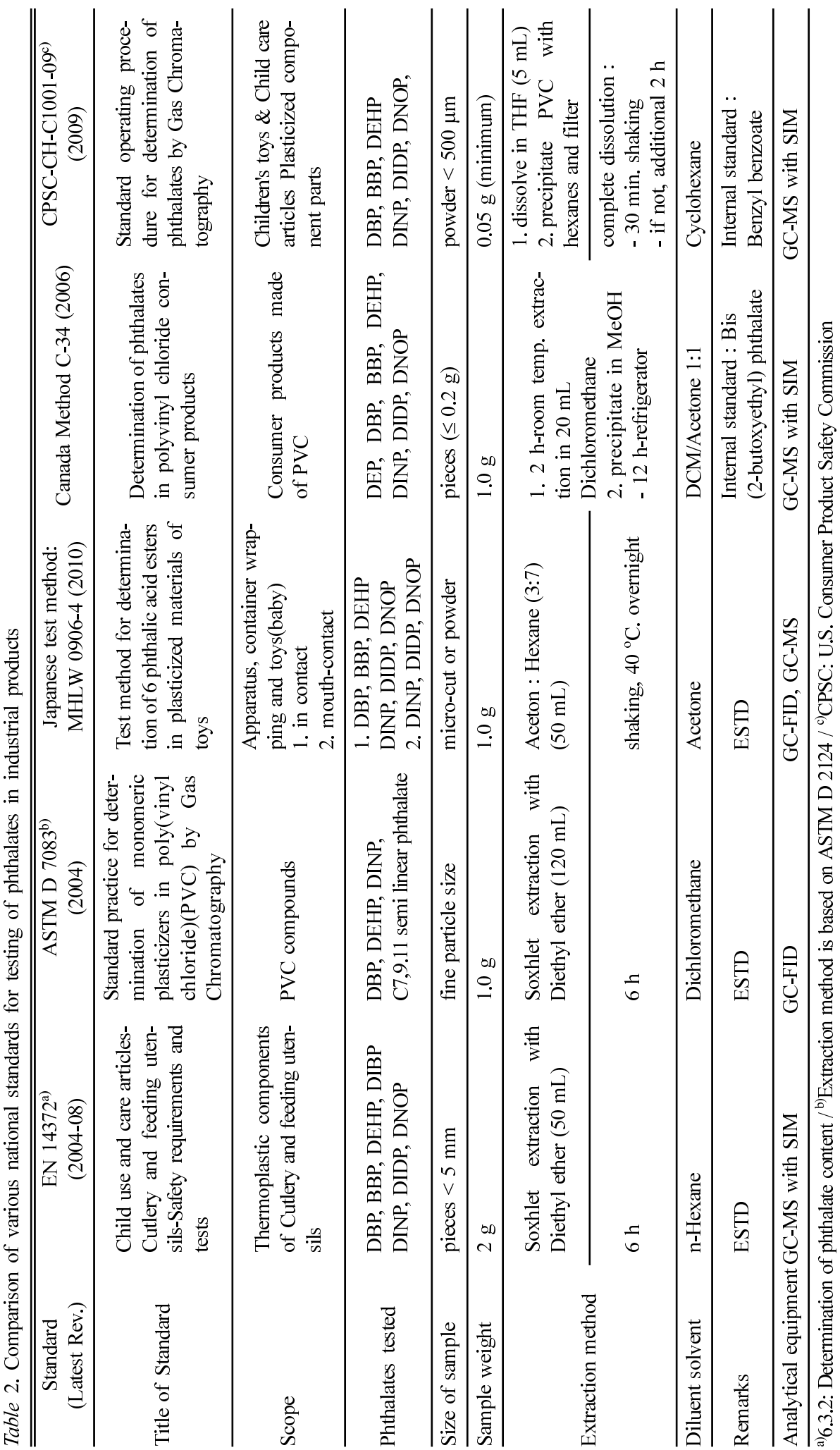


Table 3. Major feature of KS M 1991 after revision in 2011

\begin{tabular}{|c|c|c|c|}
\hline $\begin{array}{c}\text { Standard } \\
\text { (Revision date) }\end{array}$ & $\begin{array}{l}\text { KS M } 1991: 2008 \\
(2008.12 .19)\end{array}$ & \multicolumn{2}{|c|}{$\begin{array}{l}\text { KS M 1991: } 2011 \\
\quad(2011.12 .16)\end{array}$} \\
\hline \multirow{2}{*}{ Title of Standard } & \multicolumn{3}{|c|}{ Determination of phthalates contents } \\
\hline & in plastic materials & \multicolumn{2}{|l|}{ in polymer materials } \\
\hline Scope & Plastic material & \multicolumn{2}{|l|}{ Polymer material } \\
\hline Phthalates tested & $\begin{array}{l}\text { not specified } \\
\text { DEP, DBP, DEHP, DINP as a } \\
\text { GC-Mass example }\end{array}$ & \multicolumn{2}{|c|}{$\begin{array}{l}\text { DBP, BBP, DEHP, DIBP } \\
\text { DINP, DIDP, DNOP }\end{array}$} \\
\hline \multirow[b]{2}{*}{ Size of sample } & \multirow[b]{2}{*}{ ground particles $<1 \mathrm{~mm}$} & \multicolumn{2}{|c|}{ ground particles $<2 \mathrm{~mm} \times 2 \mathrm{~mm}$} \\
\hline & & $\begin{array}{l}\text { if not soluble in THF, } \\
<0.5 \mathrm{~mm} \times 0.5 \mathrm{~mm}\end{array}$ & \\
\hline Sample weight & $1.0 \mathrm{~g}$ & $0.3 \mathrm{~g}$ & $0.5 \mathrm{~g}$ \\
\hline Extraction method & $\begin{array}{l}\text { Soxhlet extraction } \\
\text { with n-hexane }(80 \mathrm{~mL}) \\
6 \mathrm{~h}\end{array}$ & $\begin{array}{l}\text { 1. dissolve in THF }(10 \mathrm{~mL}) \text { : } \\
\text { Ultrasonic, } 40{ }^{\circ} \mathrm{C}, 30 \mathrm{~min} \text {. } \\
1 \mathrm{~h} \text { if not completely soluble } \\
\text { 2. precipitate polymers with } \\
\text { ACN or } \mathrm{MeOH}(20 \mathrm{~mL}) \\
\text { 3. filter }(0.45 \mu \mathrm{m})\end{array}$ & $\begin{array}{l}\text { Soxhlet extraction } \\
\text { with n-hexane }(120 \mathrm{~mL}) \\
60 \sim 80{ }^{\circ} \mathrm{C}, 6 \mathrm{~h}\end{array}$ \\
\hline Diluent solvent & $\begin{array}{l}\text { heat to dryness / } \\
\text { n-Hexane (to } 250 \mathrm{~mL} \text { ) }\end{array}$ & - & $\begin{array}{l}\text { Concentration(to } 10 \mathrm{~mL} \text { ) } \\
\text { / } \mathrm{n} \text {-Hexane (to } 50 \mathrm{~mL} \text { ) }\end{array}$ \\
\hline Remarks & ESTD & $\begin{array}{l}\text { Internal standard : Anthracene } \\
\text { ESTD for LC-MS }\end{array}$ & 0 for GC-MS, \\
\hline Analytical equipment & GC-MS & GC-MS, LC-MS & \\
\hline
\end{tabular}

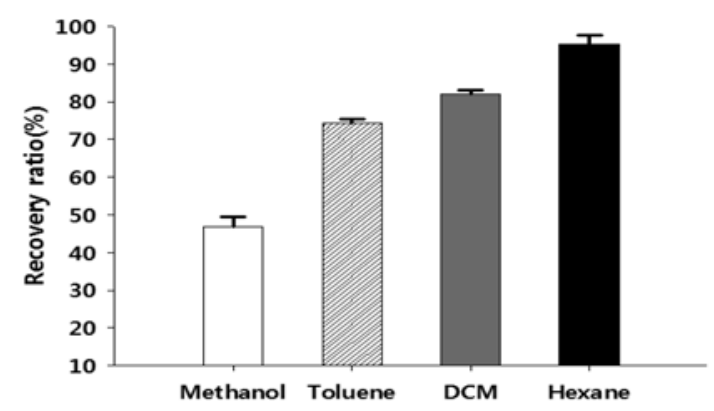

Fig. 2. Recovery ratios of Di-(2-ethylhexyl)phthalate from PVC by $6 \mathrm{~h}$-Soxhlet-extraction using different solvents.

$$
\text { 수 있다. }{ }^{22}
$$

\section{2. 최적 용매 및 최적 추출 시간의 검토}

4 가지 다른 용매를 사용하여 PVC에서 DEHP를 속 슬렛 추출 할 때의 회수율은 메탄올, 톨루엔, 디클로 로메테인 및 헥세인으로 순으로 $46.9 \%, 74.4 \%$, $82.0 \%, 95.3 \%$ 로 증가하여 헥세인이 최적 용매임을 알 수 있었고, 이는 소수성인 DEHP가 극성인 메탄올과

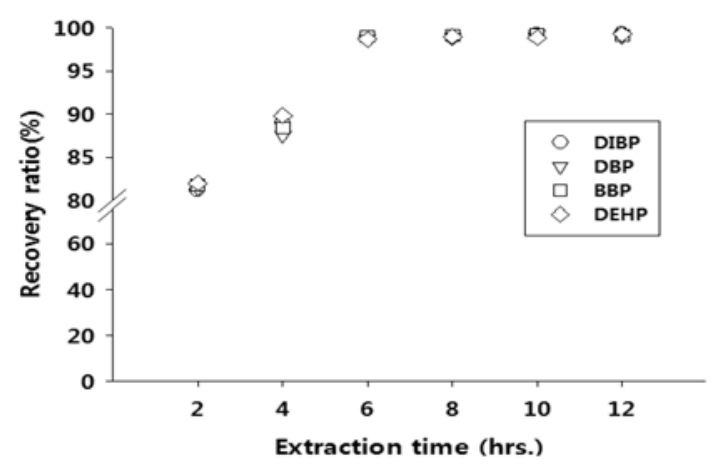

Fig. 3. Recovery ratios of phthalates from EPDM rubber using hexane according to different Soxhlet-extraction times.

디클로로메테인 보다 비극성인 헥세인에 용해도가 큰 결과로 사료된다.

$\mathrm{THF}$ 용출 전처리에 비해 속슬렛 추출 전처리는 시 간이 오래 걸리는 단점이 있어 속슬렛 추출 시간을 단축해보려는 목적으로 표준 검증을 시도하였다. $\mathrm{EPDM}$ rubber 재질은 THF 용매에 녹지 않는데, 이에 함유된 $\mathrm{DBP}, \mathrm{BBP}, \mathrm{DEHP}, \mathrm{DIBP}$ 4종 프탈레이트를 헥 

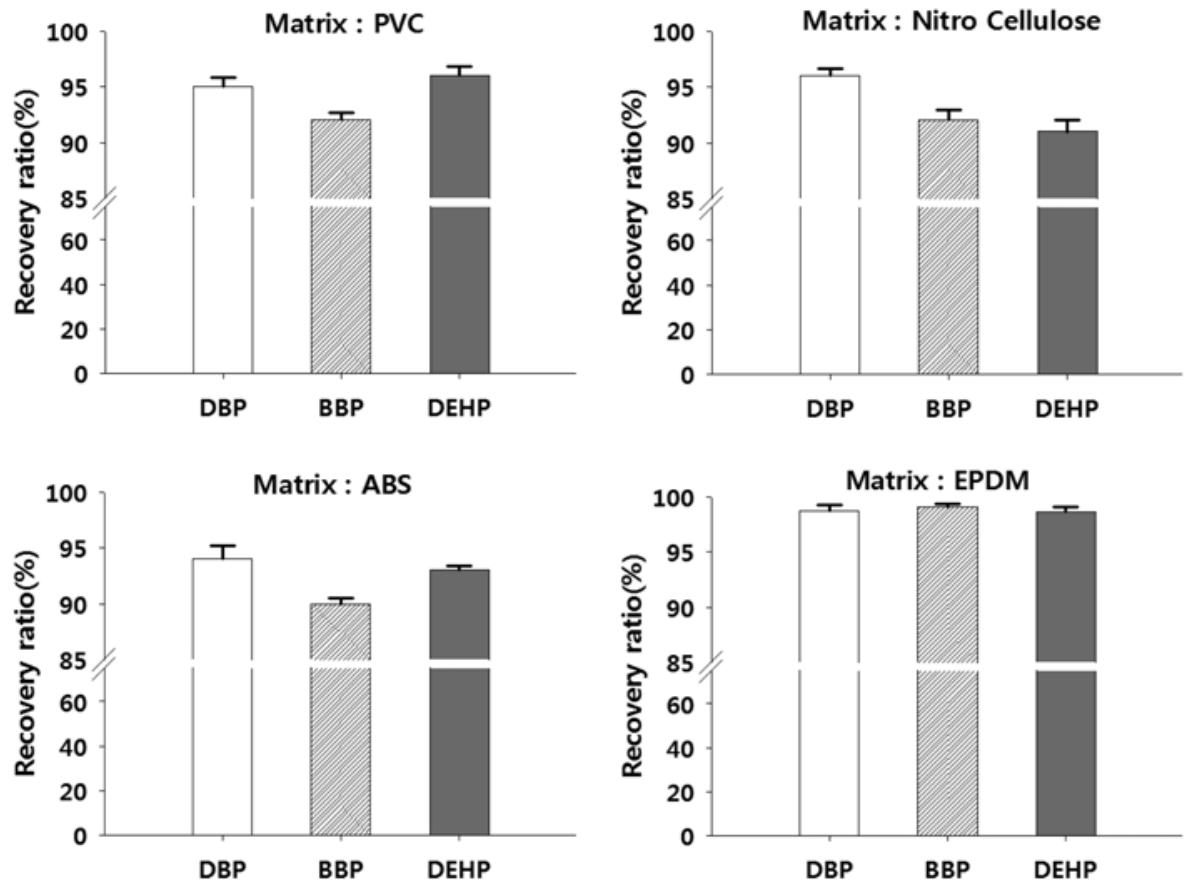

Fig. 4. Recovery ratios of phthalates from different matrixes by Soxhlet-extraction.

세인을 사용하여 시간 당 용매 순환속도가 6 회가 되도록 하여 $2,4,6,8,10,12$ 시간 동안 속슬렛 추출 하였고 결과는 Fig. 3에서 볼 수 있듯이 최적 속슬렛 추출시간이 6시간임이 입증되어 시간을 현재 표준의 6시간보다 더 단축할 수 없었다. 또한 DIBP, DBP, $\mathrm{BBP}, \mathrm{DEHP}$ 의 회수율도 거의 동일하게 측정되어 프 탈레이트 종류에 따른 차이가 없음을 알 수 있었다.

이상에서 KS M 1991에서 사용하는 추출 용매(핵세 인)와 추출 시간(6 시간)에 대한 검증이 이루어 졌다. 속슬렛 추출 시간의 단축 및 간소화를 위하여, 고압 고온 하에 2시간으로 동등한 성능을 갖는 자동 추출 장치사용에 대한 연구가 이미 보고된 바 있다. ${ }^{30}$

\section{3. 주요 소재에서의 회수율 산출 결과}

산업적으로 프탈레이트가 함유될 가능성이 있는 $\mathrm{PVC}$, nitro cellulose, ABS 및 $\mathrm{EPDM}$ rubber 재질의 매트리스에 스파이크한 $\mathrm{DBP}, \mathrm{BBP}, \mathrm{DEHP}$ 을 헥세인을 이용하여 6시간 속슬렛 추출하여 분석한 결과, 각 3종 프탈레이트 모두 90\% 99\% 범위의 회수율을 갖는 것 으로 측정되었다. 따라서 헥세인을 이용한 6 시간 속슬 렛 추출의 전처리 조건을 사용하면 매질 및 프탈레이 트 종류에 관계없이 회수율의 범위가 유의성을 갖음
을 알 수 있었다(Fig. 4).

\section{4. 프탈레이트 분석법 국가 표준 및 $\mathrm{KS}$ 의 용매} 추출 효율 비교

공산품에서 프탈레이트를 분석하는 국가 표준 중 (Table 2) 용매 추출을 전처리로 사용하는 EN 14372, ASTM D-7083, 일본 후생노동성 시험법(MHLW 09064)과 KS M 1991에 의거하여(Fig. 5(a)) 프탈레이트 추 출 효율을 실험한 결과는 Fig. 5(b)와 같다. $\mathrm{EPDM}$ rubber 소재에서 $\mathrm{DBP}, \mathrm{BBP}, \mathrm{DEHP}, \mathrm{DIBP}$ 4종 모두 98\% 99\% 범위로 추출됨이 측정되었다. 따라서 국제 표준 제정 시 용매 추출 전처리 부분에서는 유사한 추출 효율을 갖는 것으로 검증된 Fig. 5(a)의 표준을 참고로 방법의 용이성, 인체 건강 및 경제성 등을 고 려하여 제정될 수 있으리라 사료된다. EN 14372과 ASTM D-7083에서는 용매로 추출한 후, 용매를 모두 증발시키므로 비극성 용매이면서 헥세인(b.p. $69^{\circ} \mathrm{C}$ ) 보다 끓는점이 낮은 ethyl ether (b.p. $35{ }^{\circ} \mathrm{C}$ )를 사용하 였고, 최종 $\mathrm{GC}$ 분석용 용액에는 각각 헥세인 및 $\mathrm{DCM}$ 으로 희석용매로 사용하고 있다. 반면, $\mathrm{KS} \mathrm{M}$ 1991은 추출 용매부터 휘발 안정성을 갖는 헥세인을 사용하고, 추출 후 부피를 농축한 후 헥세인으로 최종 
(a) Flow charts of each test method

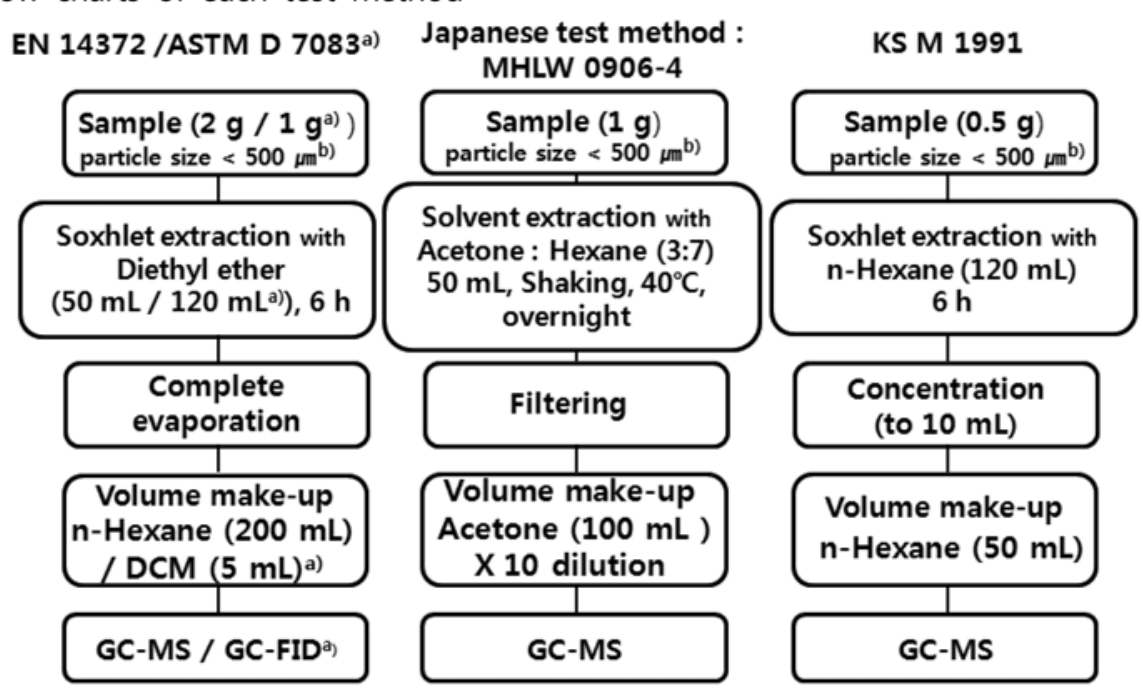

a) Difference of ASTM D 7083 from EN 14372 is described.

b) The same sample grinding was used in our experiment.

(b) the resulting recovery ratios
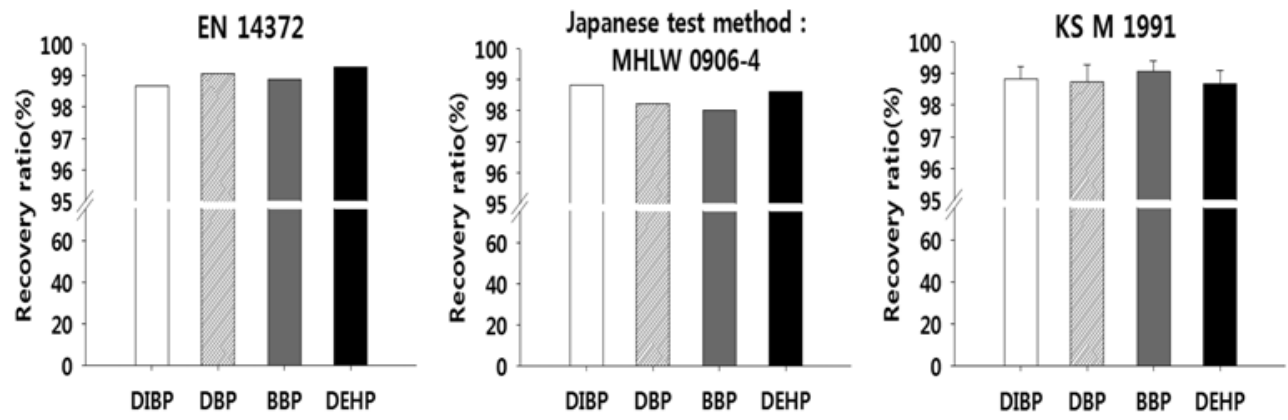

Fig. 5. Comparison of various national standards for phthalate-testing : (a) flow charts of each test method and (b) the resulting recovery ratios.

부피로 희석하고 있다.

\subsection{Memory effect}

검 량곡선을 작성하기 위해 표준용액 측정 시에 10 $\mathrm{mg} / \mathrm{L}$ 이상 농도의 용액 측정 후(Fig. 6(a)) memory effect가 관찰되었다. 즉, 고농도 시료 측정 후에, 용매 (blank)만을 측정하여도 전 시료에서 컬럼에 오염되어 남은 미량 성분이 Fig. 6(b)에서처럼 크로마토그래프 에 기록되는 현상으로 이 경우 $\mathrm{DBP}, \mathrm{BBP}, \mathrm{DEHP}$ 세 성분이 각 $10 \mathrm{mg} / \mathrm{L}$ 농도인 용액을 $1 \mu \mathrm{L}$ 주입하였을 때 기록된 양의 각 $0.5 \%, 0.35 \%, 0.4 \%$ 에 해당하는 양 만큼 오차가 나타났다. 이러한 memory effect를 제거 하기 위해서는 고농도 측정 이후 blank 용매로 컬럼
오염을 확인하고 이에 따른 컬럼의 cleaning이 필요함 을 알 수 있었다.

\section{6. 프탈레이트의 속슬렛 용매추출 후 GC-MS} 분석법의 검출 및 정량한계

DIBP, DBP, BBP, DEHP의 속슬렛 용매추출에 이은 $\mathrm{GC}-\mathrm{MS}$ 분석법의 검출 및 정량 한계는 Fig. 1 의 검량 곡선으로부터 산출한 결과, 용액 및 고분자 샘플에서 각각 $0.08 \sim 0.3 \mu \mathrm{g} / \mathrm{mL}$ 및 $8 \sim 30 \mathrm{mg} / \mathrm{kg}$ 으로 산출되었고 정량 한계는 이의 각 3 배이다(Table 4). Table 4의 고 체 샘플에서의 검출한계는 용액 검출한계로부터 희석 배율 100 배를 고려하여 계산된 값이며, 희석배율에 반 비례하므로 최종 부피를 줄이거나 추출시료의 양을 


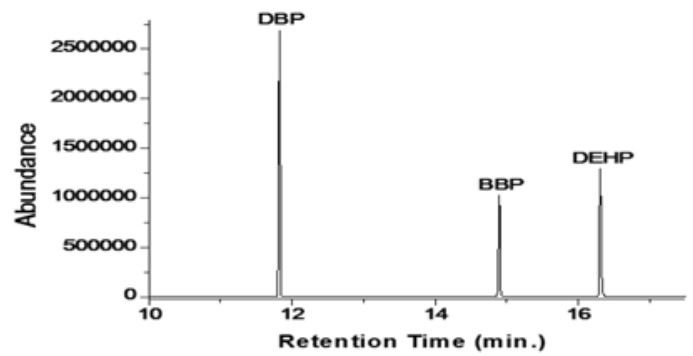

(a)

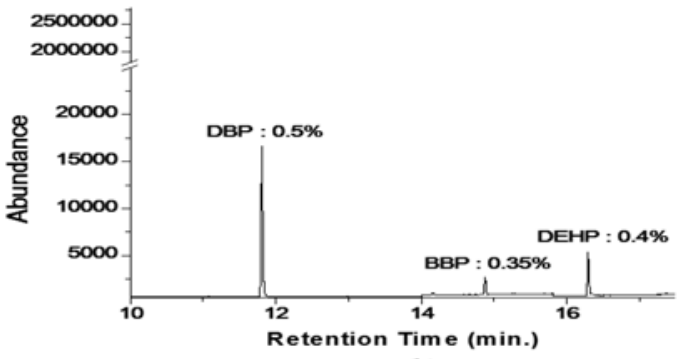

(b)

Fig. 6. GC chromatograms of (a) standard solution of phthalates with concentration of $10 \mathrm{mg} / \mathrm{L}$ of each and (b) subsequent blank solution showing a memory effect.
증가하는 방식으로 검출한계를 2 5배 정도 감소, 즉 검출을 예민하게 할 수 있다.

\section{7. 국내 공산품에서의 프탈레이트 검출 현황}

국내에서 프탈레이트가 사용되는 현황에 대한 보고 를 살펴보면, ${ }^{31-34}$ 어린이 용품에서 DINP, DEHP가 수 백 수천 $\mathrm{mg} / \mathrm{kg}$ 검출되었고 ${ }^{30}$ 먹는 샘물 및 $\mathrm{PET}$ 용기 라벨, 접착제 등에서 프탈레이트 함유 여부를 검출한 결과 라벨이나 본드에서 $\mathrm{DEP}, \mathrm{DBP}, \mathrm{DOP}$ 등이 검출되 었다. ${ }^{31}$ 저질(sediment)과 같은 환경 시료에서 8종 프탈 레이트를 분석한 결과 $\mathrm{DEP}, \mathrm{DBP}$ 및 $\mathrm{DEHP}$ 만 검출되고 다른 프탈레이트는 검출되지 않았으며, $\mathrm{DEHP}$ 가 검출 빈도 및 평균측정농도도 가장 높게 나타났다. ${ }^{32}$ 건축자 재인 Wood Plastic Composite의 DCM 추출물 분석 결과 $\mathrm{BBP}$ 를 제외한 5종 프탈레이트, DMP (dimethyl phthalate), DEP (diethyl phthalate), DBP, DEHP, DNOP가 수 수백 $\mathrm{mg} / \mathrm{kg}$ 검출되었다. ${ }^{33}$ 또한, 전기전자의 플라스 틱 부품에서 $\mathrm{DBP}, \mathrm{BBP}, \mathrm{DEHP}$ 를 분석한 결과 $\mathrm{DEHP}$ 가 가장 빈번히 고농도로 수십 수만 $\mathrm{mg} / \mathrm{kg}$ 검출되었다. ${ }^{34}$

본 연구에서는 프탈레이트를 함유할 가능성이 있는

Table 4. Limit of detection in GC-MS analysis of phthalates in industrial products

\begin{tabular}{|c|c|c|c|c|c|c|c|c|}
\hline \multirow{2}{*}{ Substance } & \multirow{2}{*}{$\begin{array}{l}\text { Concentration } \\
\text { range }(\mu \mathrm{g} / \mathrm{mL})\end{array}$} & \multicolumn{2}{|c|}{$\mathrm{Y}=\mathrm{aX}+\mathrm{b}$} & \multirow{2}{*}{$\mathrm{R}$} & \multicolumn{2}{|c|}{$\begin{array}{l}\text { Measurement in } \\
\text { solution }\end{array}$} & \multicolumn{2}{|c|}{$\begin{array}{c}\text { Measurement in } \\
\text { polymeric material }^{\text {a) }}\end{array}$} \\
\hline & & Slope(a) & Intercept(b) & & $\begin{array}{c}\text { LOD } \\
(\mu \mathrm{g} / \mathrm{mL})\end{array}$ & $\begin{array}{c}\mathrm{LOQ} \\
(\mu \mathrm{g} / \mathrm{mL})\end{array}$ & $\begin{array}{c}\text { LOD } \\
(\mathrm{mg} / \mathrm{kg})\end{array}$ & $\begin{array}{c}\mathrm{LOQ} \\
(\mathrm{mg} / \mathrm{kg})\end{array}$ \\
\hline DIBP & $1.25-10.00$ & $1,529,962$ & 36,541 & 0.999 & 0.08 & 0.24 & 8 & 24 \\
\hline DBP & $1.25-10.00$ & $1,763,971$ & 68,103 & 0.999 & 0.15 & 0.45 & 15 & 45 \\
\hline BBP & $1.25-10.00$ & 710,451 & 6,621 & 0.999 & 0.3 & 10 & 30 & 100 \\
\hline DEHP & $1.25-10.00$ & 986,984 & 67,349 & 0.999 & 0.3 & 10 & 30 & 100 \\
\hline
\end{tabular}

${ }^{a}$ In case of dilution factor $=100$

Table 5. Detection of phthalates in industrial products

\begin{tabular}{|c|c|c|c|}
\hline Samples & Matrix & $\begin{array}{l}\text { Phthalates } \\
\text { tested }\end{array}$ & $\begin{array}{c}\text { Amount measured } \\
(\mathrm{mg} / \mathrm{kg})\end{array}$ \\
\hline \multirow{3}{*}{ Power cable (Computer) } & \multirow{3}{*}{ Polyvinyl chloride } & DBP & $117(9.5)^{\mathrm{a})}$ \\
\hline & & BBP & ND \\
\hline & & DEHP & $324(10.5)$ \\
\hline \multirow{3}{*}{ Manicure } & \multirow{3}{*}{ Nitro cellulose } & DBP & $1,910(21)$ \\
\hline & & $\mathrm{BBP}$ & ND \\
\hline & & DEHP & $421(15.3)$ \\
\hline \multirow{3}{*}{ Children's Toy (Car) } & \multirow{3}{*}{ Acrylonitrile butadiene styrene copolymer } & DBP & $22(2.6)$ \\
\hline & & BBP & ND \\
\hline & & DEHP & $40(4.5)$ \\
\hline
\end{tabular}

a) Standard deviation $(\mathrm{n}=3)$ 
공산품인 어린이 장난감(자동차), 컴퓨터용 파워 케이 블, 여성용 매니큐어를 국내 시장에서 수집하여 3종 프탈레이트 함유 여부를 분석한 결과 DBP 및 DEHP 가 $22 \sim 1,910 \mathrm{mg} / \mathrm{kg}$ 범위로 검출되었고, $\mathrm{BBP}$ 는 검출 되지 않았다(Table 5). 매니큐어에서 두 종 프탈레이트 검출 사례는 소비자 보건 상 더 집중 조사가 되어야 할 주요한 사항이며, 어린이용 장난감에서 검출된 DBP $22 \mathrm{mg} / \mathrm{kg}$ 및 DEHP $40 \mathrm{mg} / \mathrm{kg}$ 의 양은 Table 4의 검출한계를 막 넘어선 값으로 정량의 의미는 없으며, 플라스틱 마스터 배치에서의 오염으로 인하여 미량 함유되었으리라 사료된다. $\mathrm{BBP}$ 의 미검출은 위에서 언 급한 몇 건의 선행 보고 ${ }^{30-34}$ 와 일치한다.

\section{4. 결 론}

프탈레이트가 유럽 신화학물질관리제도(REACH)의 허가대상 고위험성 물질(SVHC) 목록 및 유럽의 전기 전자제품에 함유된 유해물질 규제인 RoHS II의 최우 선 고려 물질 등으로 규제가 강화되어 분석법 국제표 준에 관심이 집중되고 있는 현황에서, 현존하는 국가 별 표준의 용매 추출 전처리를 비교 및 검증한 다음 의 연구 결론은 표준화 활동에 기술적 자료로 이용되 리라 사료된다.

1.PVC에서의 DEHP의 속슬렛 추출 효율은 methanol, toluene, dichloromethane 및 hexane 순으로 $46.9 \%$ 에서 $95.3 \%$ 까지 증가하였고, hexane을 사용한 $\mathrm{DBP}, \mathrm{BBP}$, $\mathrm{DEHP}, \mathrm{DIBP}$ 에 대한 최적 속슬렛 추출시간이 6 시간 임이 입증되었다.

2. PVC, nitro cellulose, ABS 및 EPDM rubber 소재 의 매트리스로부터 hexane을 이용한 6시간 속슬렛 추 출 효율은 매질 및 프탈레이트 종류에 관계없이 모두 $90 \%$ 99\% 범위임이 측정되었다.

3. EN 14372, ASTM D 7083, 일본 후생노동성 시 험법(MHLW 0906-4)과 KS M 1991에 명시된 용매추 출 효율을 비교한 결과 모두 EPDM rubber 소재에서 $\mathrm{DBP}, \mathrm{BBP}, \mathrm{DEHP}, \mathrm{DIBP}$ 4종 프탈레이트 추출 효율이 $98 \%$ 99\%임이 측정되었다.

4. $10 \mathrm{mg} / \mathrm{L}$ 이상 농도의 프탈레이트 용액에서는 용 매(blank) 측정으로 memory effect를 확인한 후 컬럼 의 cleaning이 필요함을 알 수 있었다.

5. 속슬렛 용매추출에 이은 GC-MS 분석법의 검출 한계는 용액 및 고분자 샘플에서 각각 $0.08 \sim 0.3 \mu \mathrm{g} /$ $\mathrm{mL}$ 및 $8 \sim 30 \mathrm{mg} / \mathrm{kg}$ 으로 산출되었다.

6. 국내에서 유통되는 어린이 장난감, 전기 코드, 매
니큐어의 공산품 3종에서 $\mathrm{DBP}$ 및 $\mathrm{DEHP}$ 가 22 1,910 $\mathrm{mg} / \mathrm{kg}$ 범위로 검출되었다.

\section{감사의 글}

본 연구는 지식경제부 “글로벌전문기술개발(청정생 산기반)”으로 수행된 결과이며 연구비 지원에 감사드 립니다.

\section{참고문헌}

1. Y. D. Cho, S. W. Byun, E. K. Choe and S. H. Kim, Clean Technol., 18(1), 1-13 (2012).

2. http://www.chemsec.org/images/stories/2011/chemsec/SIN List_2.0_all_378.pdf.

3. http://www.chemsec.org/images/stories/2011/chemsec/SIN List_2.0_22_new_substances.pdf.

4. AB 1108, California Toxic Toys Bill (2007.06.05), U.S.A.

5. H. R. 4030, The Federal Hazardous Substances Act (2007.10.31), U.S.A.

6. Public Law 110-314 (H. R. 4040), Consumer Product Safety Improvement Act (2008.08.14), U.S.A.

7. Cosmetic Directive 76/768/EEC (2004.09.22), EU.

8. Food Sanitation Law : MHLW Notice No.370(1959), amended (Revision of Phthalate Requirements) (2010. 09. 06), Japan.

9. Canada Consumer Product Safety Act (2010.12.10), Canada.

10. Korean Agency for Technology and Standards Notification No. 2001-367(2001.07.10), Republic of Korea.

11. Korean Agency for Technology and Standards Notification No. 2007-523(2001.07.10), Republic of Korea.

12. Regulation (EC) No 1907/2006, REACH, the European Parliament and the Council of the European Union, 2006.

13. http://echa.europa.eu/chem_data/authorisation_process/ candidate_list_table_en.asp.

14. $\mathrm{http} / / /$ echa.europa.eu/reach/authorisation_under_reach/ authorisation_list_en.asp.

15. COM (2008) 809/4, "EU Commission's recast proposal for Directive 2002/95/EC", the European Parliament, 2008.

16. http://echa.europa.eu/reach/restriction/restrictions_under_ consideration_en.asp 
17. Korean Agency for Technology and Standards Announcement No. 2010-0259(2010.08.20), Republic of Korea.

18. “Oeko-Tex Standard 100”, Ed.01/2011, Oeko-Tex International, Zuerich, 2011.

19. IEC 62321, IEC, Geneva. Switzerland, 2008.

20. J. W. Kim, New Working Item Proposal, 13th Meeting of IEC TC 111 WG 3, Melbourne, October 26, 2011.

21. KS M 1991 : 2011, Determination of phthalates contents in polymer materials.

22. KS M 1991 : 2008, Determination of phthalates contents in plastic materials.

23. National Institute for Occupational Safety and Health (NIOSH), Manual of Analytical Method No. 5522, United States, 1998.

24. EN 14372, CEN(European Committee for Standardization), 2004.

25. Food Sanitation Publication No. 0904-4(Annex) (2010. 09. 06), Ministry of Health, Labour and Welfare, Japan.
26. ASTM D 2124-99, ASTM International, United States, 2004.

27. ASTM D 7083, ASTM International, United States, 2004.

28. Test method : CPSC-CH-1001-09.1, US Consumer Product Safety Commission, United States, 2009.

29. Method C-34, Health Canada, Canada, 2006.

30. Y. Y. Kang, S. K. Shin, J. S. Park, W.-i. Kim, J. W. Chun, H. J. Heo and S.-H. Koo, Anal. Sci. Technol., 23(4), 357-362 (2010).

31. U.-S. Shin, H.-S. Ahn and H.-S. Shin, Anal. Sci. Technol., 15(5), 475-481 (2002).

32. S.-W. Myung, Y.-J. Chang, S.-H. Yoon, H.-W. Cho and M.-S. Kim, Anal. Sci. Technol., 15(4), 360-364 (2002).

33. S. Kim and H. Kim, 45th Conference of the Korean Soc. of Anal. Sci., Ramada Plaza Hotel, Jeju, 150 (2010).

34. M. H. Song, S. H. Son, Y. D. Cho and E. K. Choe, Clean Technol., 17(2), 124-133 (2011). 